\title{
Gender Representation in Current EFL Textbooks in Iranian Secondary Schools
}

\author{
Mahnaz Hall \\ School of Languages, Cultures, and Linguistics, Monash University, Melbourne, Australia
}

\begin{abstract}
This study investigates gender representation in current EFL textbooks (Right Path to English I and II) that are designed locally and taught as an obligatory subject in Iranian secondary schools. Two methods of analysis were performed. First, these textbooks were subjected to a systematic quantitative analysis with reference to: (1) gender visibility in both text and illustrations and (2) female/male-oriented topic presentation in dialogues and reading passages. Second, a qualitative analysis was undertaken by concentrating on four components of gender-role modelling: (1) male-centred language including: (a) firstness and (b) masculine generic construction; (2) gender-linked occupation possibilities; (3) distribution of household responsibilities, and (4) distribution of spare time and leisure activities. The findings revealed the degree of imbalance in gender representation in these textbooks. The paper concludes by addressing the implications of gender imbalance depicted in the textbooks for learners' perceptions.
\end{abstract}

Index Terms-ELT curriculum, gender representation, sexism, stereotyped gender roles, occupational roles, visibility in text

\section{INTRODUCTION}

Language is a system of communication which can be used to express cultural attitudes and values. It also plays an important role in establishing and maintaining social relations and "can be seen as a clear index of the way individuals negotiate with social forces" (Mills \& Mullany, 2011, p.1). Cameron (1985) highlights that the organisation of human societies depends on linguistic communication, and gender-based linguistic variation is an example of the role language plays in social functions.

The relationship between language and gender and how it is represented has been greatly disputed in sociolinguistic studies since the mid to late 1960s. Following the emergence of three books on language and gender in the 1970s: Male/Female Language by Marie Ritchie Key, Language and Sex: Difference and Dominance edited by Barrie Thorne and Nancy Henley, and Language and Women's Place by Robin Lakoff, sociolinguists have turned their attention to the influence that imbalanced representation of gender has on the position of women in contemporary society. This phenomenon is referred to as sexism or gender bias in the literature review.

Sexism is commonly considered to be discrimination against people based on their sex rather than their individual merits. In other words, sexism is a belief that one sex or gender is superior or more valuable than the other. In the words of Thomas (2004, p.76), "sexist language represents women and men unequally, as if members of one sex were somehow less completely human, less complex, and had fewer rights than members of the other sex". The role that language plays in maintaining and strengthening sexist values is very important and the reason for this is probably because "linguistic sexism is deeply rooted and far more subtle than other forms of sexism" (Porreca, 1984, p.705).

A powerful means of conveying gender-biased language is via instructional materials, in particular school textbooks as they play a crucial role in determining students' perceptions of female and male roles in society. According to Ndura (2004), the content of instructional materials significantly affects students' attitudes and dispositions towards themselves, others, and society. Early adolescence is the period of identity development when children are uncertain about who they are and what they want to become in the future. This is also the time when they receive their earliest education about norms, culture, and the world around them. Thus, English Language Teaching (ELT) curriculum needs to be examined in terms of representation of speakers, including their L1 background, social class, and gender. The present study investigates gender representation in two current English Language Teaching textbooks (Right Path to English I and II) in Iranian secondary schools.

\section{REVIEW OF THE RELATED LITERATURE}

The portrayal of gender roles in EFL/ESL textbooks has been a concern for scholars since the 1970s. Hence, there have been numerous attempts to analyse the representation of gender roles in these textbooks at all levels of education. Researchers who have conducted these studies have focused their inquiries on visual and textual presentations of female and male characters. Visual presentation refers to illustrations, which include pictures in the form of drawings and photographs, and textual presentation relates to conversations and any written content.

Some of the studies dealt with in this literature review have concentrated either on the analysis of illustrations or the analysis of textual presentations, while others have analysed both of these aspects in textbooks. In the making of a non- 
sexist dictionary, Graham (1975) with the help of some lexicographers analysed five million words from children's textbooks in the United States and found that although there are more women than men in the world, these textbooks contained over seven times as many references to men as women and more than twice as many references to boys as compared with girls. There were also three times as many wives mentioned as husbands indicating that the main characters or speakers in the text were male.

Two years later, Coles (1977) examined five of the most widely used sets of adult basic education materials. From 150 stories, it was found that men were mentioned three times more than women. In addition, 39 of the total of 61 females were housewives, whilst 106 of the total of 192 males had 73 different occupations. His study found that males mostly occupied skilled or managerial positions and were viewed to be breadwinners but females, on the other hand, were nothing more than housewives or workers.

In the same year, Nilsen (1977) in a comparison of words found in a standard English dictionary to their use in everyday vocabulary concluded that things were named after men five times more than after women, and most words that referred to women had passive roles or were restricted to nouns for helpless young animals (e.g., chic, kitten, and bunny), whereas words that referred to men indicated more active roles and described dominant male animals (e.g., wolf, buck, and stud).

Britton and Lumpkin (1977) in a study to determine the effectiveness of new guidelines aiming at correcting sexist levels in reading, literature, and social studies textbooks compared pre 1970 textbooks with the ones published after 1970. They reported that the number of major characters that were female had increased by only $2 \%$ in early editions and up to $16 \%$ in much later editions.

One year later, Arnold-Gerrity (1978) in completing a content analysis of nine primary reading textbooks examined the involvement of females in character roles. In the first four books, for grades one and two, she found there were twice the number of male characters as female, while in the three readers, for grades three and four, male-oriented stories were five times more frequent; and in the remaining two textbooks, for grades five and six, males appeared three times more frequently than females. Further to this, she discovered that the occupational roles for males in the textbooks were wide and varied, while for females, they were narrow and restricted to being housewives or mothers caring for the family unit.

The three most relevant studies of gender bias in ESL/EFL textbooks appeared from 1978: Sexism and TESOL Materials by Hartman and Judd (1978); For Men Must Work, Women Must Weep: Sexism in English Language Textbooks Used in German Schools by Hellinger (1980); and Sexism in Current ESL Textbooks by Porreca (1984).

In 1978, Hartman and Judd conducted a survey of several textbooks and observed that not only did women suffer from low visibility, but the references to females in the text were considerably outnumbered by references to males. This was established by counting the sex-linked proper names, titles, and non-generic pronouns. For example, in one of the books that they examined, the ratio of male to female references was $63 \%$ to $37 \%$. They also demonstrated that women's roles were stereotypical and related to children and household chores that were exemplified by cooking, changing diapers, or doing the laundry. Men, on the other hand, were depicted fixing the car, changing light bulbs, or mowing the lawn. Therefore, they concluded that "since sexist usage is built into our language habits, it is little wonder that textbooks, including ESL texts, model this usage to their students" (p. 390).

Hellinger (1980) conducted a study of 131 passages from three ELT textbooks used in German schools and found that men were involved in $93 \%$ of the passages, while $30 \%$ of the textbooks did not include any women at all. It was also revealed that unlike men who were always portrayed in occupational roles of some social status, women had uninteresting, undemanding, and less than successful positions.

In the third seminal study, Porreca (1984) conducted a content analysis of the then 15 most widely used ESL textbooks and focused on measurable categories of omission and occupational visibility in text and illustrations, firstness, masculine generic constructions, and the frequency of the use of nouns and adjectives representing men and women. In every category of her study, she found evidence that "sexism continues to flourish in ESL materials", and despite the fact that "females comprise slightly over half the population of the United States, they are depicted or mentioned only half as often as males in both text and illustrations" (pp.718-719).

Another study in the 1980s was the content analysis of 41 Indian high school, higher secondary, and pre-university curricula textbooks from five different areas of India. The findings of this study revealed that instead of highlighting women and men as equals, textbooks in India gave school children the message that men have the dominant position in all aspects of Indian society (Kalia, 1980).

Progressing into the 1990s, there are three studies worth mentioning, beginning with Sleeter and Grant (1991) who examined 47 textbooks used in grades one to eight between 1980 and 1988 in the United States. They discovered that although women were depicted in non-traditional roles in social studies, reading and language, arts, science, and mathematics textbooks, it was totally unacceptable for men to be depicted in traditionally female roles (e.g., nurse or secretary).

In 1992, Peterson and Kroner conducted a content analysis of 27 textbooks for introductory psychology and 12 for human development courses to identify if there were any examples of gender bias in these textbooks. Their findings demonstrated that females were frequently portrayed in negative and gender biased ways. Five years later, Poulou (1997) 
in examining the differences in the discourse roles of men and women in the dialogues of textbooks for teaching Greek as a foreign language revealed that sexist differences had adverse effects on pedagogical values.

Since 2000, most of the major studies on this subject have been undertaken in Asian and Middle Eastern countries including Iran, Turkey, Pakistan, Hong Kong, and Jordan. For instance in Iran, Ansary and Babaii (2003) explored the status of sexism in the 1999 edition of the same textbooks (Right Path to English I and II) that are used as the corpus of the current study and found that based on the frequency of occurrence, women suffered most from low visibility. The ratio of females to males in text was 1:1.4 and in illustrations was 1:1.6. Moreover, in an examination of female/maleoriented topic presentation in dialogues and reading passages, they demonstrated that of the total of 40 topics presented, $27(67.5 \%)$ of topics were male-dominated. They also reported that the occupational capacities in which women were portrayed appeared to be mostly restricted to occupations such as student and nurse, whereas men enjoyed a diversity of jobs such as policeman, soldier, dentist, farmer, doctor, and teacher.

In the case of the distribution of spare time and leisure activities, it was mentioned that "females were fundamentally shunted into indoor passive activities such as sitting in the classroom, watching TV at home, reading, etc." (Ansari \& Babaii, 2003, p.9). Regarding male-centred language, they discovered the usage of paired nouns such as uncle and aunt, brother and sister, boys and girls where the masculine noun always comes first. Moreover, generic pronouns reflected males as the default or unmarked gender, even pronouns such as you, $I$, and we which can be equally used to describe female or male subjects were associated with pictures illustrating men. Overall, they concluded that Right Path to English I and II are sexist textbooks that present students with an unfair and inexcusable view of women in their early exposure to the English language.

Özdoğru, Aksoy, Erdoğan, and Gök (2004) in a content analysis of two course books used in the third grade of Turkish elementary schools found that females were depicted with traditional feminine traits such as being 'hardworking, loving, caring, and child-raising'. On the contrary, male figures were presented as having the traits of 'self-confidence, decisiveness, and adventurousness'. They also demonstrated that in many family communications, while the father was the source of information for the child, the mother was presented in a more supportive role and consequently, the role for caring for younger siblings was assigned to older sisters instead of older brothers in many instances, which is parallel with the patriarchal values of Turkish society.

In the same year, a comprehensive study was conducted in Pakistan by Mirza (2004), in which she analysed 194 textbooks in six different subjects to determine the different portrayal of gender. The conclusions drawn from her study are too numerous to mention as she gave a percentage breakdown of each of the 194 textbooks analysed, including the results from surveyed interest groups. However, the overriding outcome from nine detailed conclusions was that references to females were outnumbered in all circumstances by references to males.

Two years later, in another study in Hong Kong, Lee and Collins (2006) selected 20 English language textbooks used by the Education Department of Hong Kong and compared them to the previous books that were published in the late 1980s and early 1990s. The results suggested that although many authors of textbooks these days use various strategies to avoid biased treatment of the two genders, there is still much room for improvement as women are still commonly associated with home duties, have passive roles, and mentioned less frequently than men in both written and visual modes.

More recently, Hamdan (2010) looked at a series of English language textbooks distributed in Jordan and found that out of 78 jobs, men occupied $62(79 \%)$ which portrayed them as the dominant characters in the labour market despite the fact that nowadays, Jordanian women hold diverse positions such as government ministers, members of parliament, police officers, and taxi drivers.

\section{METHODOLOGY}

\section{A. Materials}

Two EFL textbooks currently used in Iranian secondary schools were selected to serve as the corpus of the present study. The description of the textbooks is presented in (Table 1):

TABLE 1

DESCRIPTION OF THE TEXTBOOKS

\begin{tabular}{|l|l|l|l|l|}
\hline Title & Publisher/Authors & Grade & $\begin{array}{l}\text { Date of } \\
\text { Publication }\end{array}$ & $\begin{array}{l}\text { Number of } \\
\text { Pages }\end{array}$ \\
\hline $\begin{array}{l}\text { Right Path to } \\
\text { English I }\end{array}$ & $\begin{array}{l}\text { Iranian Ministry of Education } \\
\text { (Birjandi \& Babaii) }\end{array}$ & 7 & 2012 & 97 \\
\hline $\begin{array}{l}\text { Right Path to } \\
\text { English II }\end{array}$ & $\begin{array}{l}\text { Iranian Ministry of Education } \\
\text { (Birjandi \& Babaii) }\end{array}$ & 8 & 2012 & 85 \\
\hline
\end{tabular}

\section{B. Data Collection Analysis}

Two methods of analysis were undertaken. First, these textbooks were subjected to a systematic quantitative analysis with reference to: (1) gender visibility in both text and illustrations and (2) female/male-oriented topic presentation in dialogues and reading passages. Second, in order to develop a more comprehensive picture of the gender-role 
stereotyping in these textbooks, a qualitative analysis was carried out by concentrating on four components of genderrole modelling: (1) male-centred language including: (a) firstness and (b) masculine generic construction; (2) genderlinked occupation possibilities; (3) distribution of household responsibilities, and (4) distribution of spare time and leisure activities.

\section{Procedures}

The procedures in this study were in two stages. The first stage focused on counting the number of occurrences of females and males in both text and illustrations and the results were summed up and tabulated, together with the total number of times that female/male-oriented topics were presented in dialogues and reading passages.

In the second stage, an inquiry was made into the use of male-centred language. To assess the extent of this, instances of firstness in which males or females were presented first in reading passages, dialogues, examples, and exercises were considered. In addition, the usage of masculine generic constructions whether they were either truly intended to be generic (inclusive of both genders) or merely male-referenced, along with the use of all masculine nouns, adjectives, and pronouns as all-inclusive terms for both genders were highlighted. Next, the occupation possibilities for females and males were identified and tabulated. Then, the household responsibilities of females such as cooking, cleaning, shopping, and mending were paired with their male counterparts and the results of the distribution were tabulated. Finally, spare time and leisure activities that allow individuals to relax their minds and engage in physical outlets such as sport, walking in the park, or going out with friends were investigated and tabulated.

\section{THE ANALYSIS OF FINDINGS}

The analysis of the collected data is divided into two sections. Section A shows the results of the quantitative analysis and is presented in two parts: part (1) gender visibility in both text and illustrations and part (2) female/male-oriented topic presentation in dialogues and reading passages. Section B determines the qualitative analysis of the corpus and is presented in four parts: part (1) male-centred language; part (2) gender-linked occupation possibilities; part (3) distribution of household responsibilities, and part (4) distribution of spare time and leisure activities.

Section A. The Quantitative Analysis

Part 1. Gender Visibility in Individual Text and Illustrations

TABLE 2

GENDER VISIBILITY IN INDIVIDUAL TEXT AND ILLUSTRATIONS

\begin{tabular}{|c|c|c|c|c|c|c|}
\hline \multicolumn{4}{|l|}{ Male } & \multicolumn{3}{|l|}{ Female } \\
\hline & $\mathrm{T}$ & I & Total & $\mathrm{T}$ & I & Total \\
\hline Textbook & 323 & 287 & 610 & 185 & 177 & 362 \\
\hline $\mathrm{I}$ & $62.5 \%$ & $62 \%$ & $62.5 \%$ & $36.5 \%$ & $38 \%$ & $36.5 \%$ \\
\hline Textbook & 417 & 111 & 528 & 284 & 78 & 362 \\
\hline II & $60 \%$ & $59 \%$ & $59.5 \%$ & $40 \%$ & $41 \%$ & $40.5 \%$ \\
\hline
\end{tabular}

Note $1 . \mathrm{T}=\mathrm{Text}, \mathrm{I}=$ Illustrations

Note 2. All percentages are rounded to the nearest whole number. Due to the rounding, they may not add up to $100 \%$

As presented in (Table 2), female and male characters appeared 972 times in text and illustrations throughout Textbook I. A comparison between the percentages of female figures (36.5\%) and male figures $(62.5 \%)$ shows a difference of (26\%) suggesting that there is a sharp numerical imbalance in the visibility of female and male characters in individual text and illustrations, which implies that men are dominant in terms of appearance.

In Textbook II, of the total of 890 characters, 362 were female and 528 were male. In other words, female characters comprised (40.5\%) and male characters (59.5\%) in individual text and illustrations. This indicates a (19\%) difference between the gender representations, and although this result does not imply as large a difference as (26\%) in Textbook I, it still reveals a surprising asymmetry between the two genders.

Part 2: Female/Male-Oriented Topic Presentation in Dialogues and Reading Passages

TABLE 3

FEMALE/MALE-ORIENTED TOPIC PRESENTATION IN DIALOGUES AND READING PASSAGES

\begin{tabular}{|l|l|l|l|l|l|l|l|l|l|l|l|l|l|}
\hline & Male only & Female only & Malemale \\
\hline
\end{tabular}




\begin{tabular}{|c|c|c|c|c|c|c|}
\hline Textbook & Dialogue & $12(47 \%)$ & $11(43 \%)$ & $1(4 \%)$ & $2(6 \%)$ & 26 \\
\hline I & Reading & $2(50 \%)$ & $2(50 \%)$ & 0 & 0 & 4 \\
\hline Textbook & Dialogue & $7(46 \%)$ & $8(50 \%)$ & $1(4 \%)$ & 0 & 16 \\
\hline II & Reading & $7(89 \%)$ & $1(11 \%)$ & 0 & 0 & 8 \\
\hline
\end{tabular}

As illustrated in (Table 3), the results of female/male-oriented topic presentation in dialogues in Textbook I revealed that of the total of 26 topics, $12(47 \%)$ were male and 11(43\%) were female-oriented. However, in 1 dialogue (4\%), an interaction between female/male characters was observed and two dialogues $(6 \%)$ were sex-neutral. In the reading passages in Textbook I, of the total of 4 topics, 2(50\%) were male topics and the remaining 2(50\%) were female topics which shows a symmetry in female/male-oriented topic presentations.

On the other hand, in Textbook II, of the total of 16 dialogues, 7(46\%) of the topics were male-referenced and $8(50 \%)$ were female-referenced, surprisingly enough for the first time it was observed that females outnumbered males. Furthermore, in 1 dialogue (4\%), an interaction between female/male characters was observed. In the reading passages in Textbook II, after observing the surprising results in dialogues, the converse of this applied as out of the total of 8 passages, 7(89\%) were male-referenced and only $1(11 \%)$ was female-referenced which demonstrates a sharp difference of $(78 \%)$.

\section{Section B. The Qualitative Analysis}

Part 1. Male-Centred Language

\section{Textbook I}

In this textbook, three instances of firstness were observed and examples are given below:

(1) On page 26, in introducing the family members, the reading passage began with "This is Amir's family. This is Mina". This sentence shows male firstness when the family could have just as easily been introduced as Mina's family, a female character.

(2) On page 51 where a sister and brother were studying together, the boy states: "My sister and I study our books every day". However, it could have also been appropriate for the girl to have spoken the sentence.

(3) On page 89, in exercise D, the sentence "My father and mother eat lunch at 12" demonstrates the male dominance as the father was mentioned before the mother.

In this textbook, generic pronouns were basically intended to include both genders; however, they mostly highlighted males as the default gender that is everyone is a male unless specified otherwise. In the case of the pronouns $I$, you, and we that can be used equally for female or male subjects, they were usually associated with pictures illustrating men. Moreover, there was very little use of adjectives in this textbook due to the simplicity of the elementary English being taught; however, females were portrayed as being sick far more often and their illnesses more severe than those of males.

In all illustrations throughout Textbook I, except in the case of a family group, there were no examples of mixed gender conversation or activities, that is to say males were always with males and females with females. For example on page 56, a boy was illustrated to be thinking about a friend who was a boy, or on page 6 when a female was driving a car, all the passengers were female. In addition, where generic parts of the human body such as hands and arms (p.4) and features of a face (p.27) were depicted, they always were restricted to male body parts. Furthermore, there were six instances where all objects such as jackets, shoes, hats, and combs in the illustrations belonged to men and only in one illustration (p.49), the objects such as a dress, a scarf, and a Tee shirt could be considered solely owned by women.

\section{Textbook II}

In this textbook, three instances of firstness were observed and examples are provided below:

(1) On page 37, in Review (2), Section (C) “My brother is tall: but my sister is short" reveals the firstness of the male character.

(2) On page 46, in a reading passage it was mentioned that "Nahid went to Shiraz and she stayed at her grandfather's house"; however, it could have been stated that she stayed at her grandmother's house.

(3) On page 64, the reading passage began with "Mr Kamali and his family are from Tehran". Once again, the sentence could have been written from the context of Ms Kamali and her family.

Generic pronouns used in this textbook were basically intended to include both genders; however, they mostly highlighted males as the default gender. In the case of the pronouns $I$, you, and we that can be used equally for female or male subjects, they were usually associated with pictures illustrating men. In considering the use of adjectives, although they were confined to Lesson One in which simple adjectives such as tall, short, old, and young were mentioned, the authors chose to use them in such a way as to denigrate females. For example on page 10 , it was mentioned that " $M r$ Hamidi is a teacher. He is young, Mrs Amini is a woman. She is old". Further to this, in an illustration Mrs Amini was portrayed as a very old and wrinkled female.

Once again, there was segregation of the genders except within a family group. However, there was a more even distribution of generic objects belonging to females and males in illustrations than there was in Textbook I.

Part 2. Gender-Linked Occupation Possibilities 
GENDER-LINKED OCCUPATION POSSIBILITIES IN TEXTBOOK I

\begin{tabular}{|l|l|}
\hline Gender-linked occupation possibilities in Textbook I \\
\hline Female & Male \\
\hline Nurse & Surgeon \\
Teacher & Teacher \\
Librarian & Policeman \\
Doctor & Doctor \\
Housekeeper & Farmer \\
& Bus driver \\
& Soldier \\
& Shopkeeper \\
& Dentist \\
\hline
\end{tabular}

As shown in (Table 4), males were presented in a wider range and overall a higher level of employment than females in Textbook I. A close examination indicates that women occupied positions such as housekeeper, nurse, teacher, and librarian, with an exception of the portrayal of a woman as a doctor on page 84. In contrast, men enjoyed greater diversity of occupations ranging from lower ranking roles such as bus driver, farmer, and shopkeeper to higher ranking roles such as surgeon, dentist, teacher, and doctor.

TABLE 5

GENDER-LINKED OCCUPATION POSSIBILITIES IN TEXTBOOK II Gender-linked occupation possibilities in Textbook II

\begin{tabular}{|l|l|}
\hline Female & Male \\
\hline Driving instructor & Professional runner \\
English teacher & Teacher \\
Nurse & Doctor \\
Farm worker & Farmer \\
Housekeeper & Bus driver \\
& Shopkeeper \\
\hline
\end{tabular}

Based on the results shown is (Table 5), males and females had almost an equal number of job possibilities with almost the same ranking as each other, which could be interpreted that Textbook II has an encouraging message that job possibilities should be equal for both genders.

\section{Part 3. Distribution of Household Responsibilities}

TABLE 6

DISTRIBUTION OF HOUSEHOLD RESPONSIBILITIES IN TEXTBOOK I

\begin{tabular}{|l|l|l|}
\hline Household responsibility in Textbook I & Female & Male \\
\hline Nursing the baby & $*$ & - \\
\hline Serving the meal & $*$ & - \\
\hline Setting the table for the meal & $*$ & - \\
\hline Cleaning the house & $*$ & - \\
\hline Making tea & $*$ & - \\
\hline Shopping & - & $*$ \\
\hline Driving & $*$ & $*$ \\
\hline Cooking dinner & $*$ & - \\
\hline Helping mother to set the table & $*$ & - \\
\hline
\end{tabular}

Note: (*) Indicates household responsibility

An evaluation of the distribution of household responsibilities shown in (Table 6) reveals the sad reality that out of the total of ten household responsibilities, eight were performed by females in the family, mothers and daughters, whereas males were only responsible for shopping and sharing the driving of the family car with females.

TABLE 7

DISTRIBUTION OF HOUSEHOLD RESPONSIBILITIES IN TEXTBOOK II

\begin{tabular}{|l|l|l}
\hline Household responsibility in Textbook II & Female & Male
\end{tabular}




\begin{tabular}{|l|l|l|}
\hline Taking the children to the park & - & $*$ \\
\hline Washing the dishes & $*$ & - \\
\hline Setting the table for the meal & $*$ & - \\
\hline Cleaning the house & $*$ & - \\
\hline Cleaning the radio & - & $*$ \\
\hline Shopping & $*$ & $*$ \\
\hline Driving & $*$ & $*$ \\
\hline Cooking dinner & $*$ & - \\
\hline Helping mother in the kitchen & $*$ & - \\
\hline Washing the car & - & $*$ \\
\hline Baking a cake & $*$ & - \\
\hline
\end{tabular}

Note: $(*)$ Indicates household responsibility

The findings illustrated in (Table 7) highlight that out of eleven household responsibilities, five were performed by females which were based around duties in the home that could not be avoided, whereas males were only responsible for three activities, one being a leisure activity of going to the park. It should be noted that both females and males were engaged in sharing two activities of shopping and driving which were both outside the home.

\section{Part 4: Distribution of Spare Time and Leisure Activities}

TABLE 8

DISTRIBUTION OF SPARE TIME AND LEISURE ACTIVITIES IN TEXTBOOK I

\begin{tabular}{|l|l|l|}
\hline Spare time \& leisure activities in Textbook I & Female & Male \\
\hline Playing ping pong & $*$ & $*$ \\
\hline Setting up a computer & $*$ & - \\
\hline Listening to the radio & - & $*$ \\
\hline Playing football & - & $*$ \\
\hline Reading a newspaper & $*$ & $*$ \\
\hline Graffiti artist & - & $*$ \\
\hline Sitting in the park & $*$ & - \\
\hline Playing in the park & - & $*$ \\
\hline Eating at a restaurant & $*$ & - \\
\hline Reading a book & $*$ & $*$ \\
\hline Watching television & $*$ & $*$ \\
\hline Talking on the telephone & - & $*$ \\
\hline Writing a letter & $*$ & - \\
\hline At the art gallery & $*$ & - \\
\hline Praying & $*$ & $*$ \\
\hline
\end{tabular}

The list of spare time and leisure activities in (Table 8) presents fifteen different activities performed by both female and male characters in Textbook I. A close look at this table reveals the equal distribution of spare time and leisure activities between both genders. In addition, female activities are not restricted to passive indoor activities such as watching television or reading a newspaper as they also enjoyed active outdoor roles such as playing ping pong, visiting the art gallery, and eating at a restaurant.

TABLE 9

DISTRIBUTION OF SPARE TIME AND LEISURE ACTIVITIES IN TEXTBOOK II

\begin{tabular}{|l|l|l|}
\hline Spare time \& leisure activities in Textbook II & Female & Male \\
\hline Playing ping pong & - & $*$ \\
\hline Taking the children to the zoo & - & $*$ \\
\hline Praying & $*$ & $*$ \\
\hline Playing football & - & $*$ \\
\hline Reading a newspaper & $*$ & $*$ \\
\hline Doing a crossword & - & $*$ \\
\hline Sitting in the park & $*$ & $*$ \\
\hline Going to the movies & - & $*$ \\
\hline Swimming & - & $*$ \\
\hline Reading a book & $*$ & $*$ \\
\hline Watching television & $*$ & - \\
\hline Going to a football stadium & - & $*$ \\
\hline Writing a letter & - & $*$ \\
\hline Riding a bike & - & $*$ \\
\hline
\end{tabular}

As presented in (Table 9), females only took part in four indoor activities such as reading a book, watching television, praying, and reading a newspaper, and only on one occasion, a woman could be seen spending her time in the park (p.3). On the contrary, males performed thirteen different indoor and outdoor activities such as going to the movies or a 
football stadium, swimming, riding a bike, taking the children to the zoo, and doing a crossword. It is obvious that females were fundamentally shunted into indoor passive activities.

\section{DISCUSSION}

The analysis of findings showed that there is an imbalance in gender representation in current Iranian EFL textbooks (Right Path to English I and II). These findings are similar to that of many studies into gender bias in EFL/ESL materials since the 1970s, for example, (Hartman \& Judd, 1978; Kalia, 1980; Porreca, 1984; Peterson \& Kroner, 1992 ; Özdoğru, Aksoy, Erdoğan, \& Gök, 2004; Lee \& Collins, 2006).

A comparison of findings with the small scale study conducted by Ansari \& Babaii (2003) on the same textbooks (1999 edition) demonstrated that in Textbook I, male-referenced text increased from 56\% in the 1999 edition to $62.5 \%$ in the 2012 edition, which is a negative increase of $6.5 \%$ illustrating that after thirteen years, women still suffered from low visibility. Furthermore, male-referenced illustrations remained at the same percentage of $62 \%$ reinforcing the lack of change in the status of women in this textbook. In Textbook II, male-referenced text remained at the same percentage of $60 \%$, whereas female-referenced illustrations improved by $2 \%$ from $39 \%$ to $41 \%$, which is a marginal increase but at the very least, it is in the right direction.

In Textbook I, male-referenced dialogues reduced from $64 \%$ in the 1999 edition to $47 \%$ in the 2012 edition which is a reduction of $17 \%$ illustrating a very positive shift towards female participation in topic presentation. There was also an increase of $6 \%$ in gender-neutral dialogues which indicates another positive change. Furthermore, male-referenced reading passages remained at the same percentage of 50\% representing the equality of the genders in this textbook. In Textbook II, male-referenced dialogues dropped from $62 \%$ to $46 \%$ which is a reduction of $16 \%$ demonstrating another positive shift towards female participation in topic presentation. In fact, female-referenced dialogues increased to a percentage of $50 \%$, which is higher than the male percentage. There was also an increase of $4 \%$ in female/male topic presentations; however, male-referenced reading passages increased from $82 \%$ to $89 \%$, showing a disappointing result from what was expected after getting positive results in female-referenced dialogues.

In considering occupational possibilities, the previous findings revealed that females appeared to be mostly restricted to occupations such as student or nurse, and in some instances, they were seen to be working in jobs such as teacher or doctor. On the contrary, new findings demonstrated that female occupational possibilities were more diverse and included three more choices such as driving instructor, librarian, and farm worker. It should be noted that in Textbook II, both genders had almost an equal number of job possibilities with almost the same ranking as each other, which could be interpreted that this textbook has an encouraging message that job possibilities should be equal for both genders.

In the case of the distribution of spare time and leisure activities, in the previous research it was mentioned that "females were fundamentally shunted into indoor passive activities such as sitting in the classroom, watching TV at home, reading, etc" (Ansari \& Babaii, 2003, p.9). Nevertheless, in the new findings, female activities were not restricted to passive indoor activities as they also enjoyed active outdoor roles such as playing ping pong, visiting the art gallery, and eating at a restaurant, which indicates a change in attitude towards females.

Regarding male-centred language, the previous research discovered the usage of paired nouns such as uncle and aunt, brother and sister, boys and girls where the masculine noun always comes first. However, in the recent study, only one instance of paired nouns, father and mother, was observed. Moreover, in the previous research, generic pronouns reflected males as the default or unmarked gender, even pronouns such as you, $I$, and we which can be equally used to describe female or male subjects were associated with pictures illustrating men. Unfortunately, the new findings revealed no improvement in the use of the generic pronouns as the results were exactly the same.

An examination of the distribution of household responsibilities revealed that the previous research found females in more traditional stereotypical roles such as doing the dishes, cooking, serving food, setting the dinner table, and taking care of the children. The sad reality is that the findings of the new research highlight the same biased results.

\section{CONCLUSION}

The analysis of findings revealed that there is an imbalance in gender representation in ELT curriculum in Iran. As English language teaching and learning in Iran is based on "a rigidly anti-imperialist ideology alongside indigenization and localisation" (Borjian, 2013, p.13), the state-run education programs are indigenised to meet the country's cultural and religious ideologies. Although this study showed improvement to some areas of the textbooks when compared with the results of the previous research which examined the same textbooks (1999 edition), there is still more room for improvement to provide an equal opportunity for learning for all students.

A pedagogical implication is that ELT curriculum in Iran needs to be examined as the content of instructional materials significantly affects students' attitudes, dispositions, and their understanding of norms, culture, and the world around them. Therefore, Educational Authorities should provide guidelines for the use of fair treatment of gender in all aspects of textbook design such as equal visibility for female and male characters and equal female/male-oriented topic presentations in dialogues and reading passages with a wider range of occupational possibilities and personal traits. In 
addition, further research needs to be undertaken on a wide range of current ESL/EFL textbooks to explore issues of representations of speakers, in particular gender representation.

\section{REFERENCES}

[1] Ansary, H. \& E. Babaii (2003). Subliminal Sexism in Current ESL/EFL Textbooks. Asian EFL Journal 5, $200-241$.

[2] Arnold-Gerrity, D. (1978). Sex Stereotyping of Women and Girls in Elementary Textbooks and its Implication for Future Work Force Participation. Paper presented at the North Central Sociological Association, Cincinnati, May 1978 (ERIC Document Reproduction Service; ED 191087).

[3] Birjandi, P. \& A. Soheili (2012). Right Path to English I and II. Iran, Tehran: Ministry of Education, Center for the Publication of University Textbooks.

[4] Borjian, M. (2013). English in Post-Revolutionary Iran: From Indigenization to Internationalization. Bristol, Buffalo and Toronto: Multilingual Matters.

[5] Britton, G. \& M. Lumpkin (1977). For Sale: Subliminal Bias in Textbooks. The Reading Teacher 31.1, $40-45$.

[6] Cameron, D. (1985). Feminism and Linguistic Theory. Great Britain: The Macmillan Press Ltd.

[7] Coles, G. (1977). Dick and Jane Grow Up: Ideology in Adult Basic Education Readers. Urban Education 12.1, 37-53.

[8] Graham, A. (1975). The Making of a Non-Sexist Dictionary. In B. Thorne \& N. Henley (eds.), Language and Sex: Difference and Dominance. Rowley, MA: Newbury House, 57-63.

[9] Hamdan, S. (2010). English-language Textbooks Reflect Gender Bias: A Case Study in Jordan. Advances in Gender and Education 2, 22-26.

[10] Hartman, P. L. \& E. L. Judd (1978). Sexism and TESOL Materials. TESOL Quarterly 12.4, 383-393.

[11] Hellinger, M. (1980). For Men Must Work, and Women Must Weep: Sexism in English Language Textbooks Used in German Schools. In C. Kramerae (eds.), The Voices and Words of Women and Men. New York: Pergamon Press, 267-274.

[12] Kalia, N. N. (1980). Images of Men and Women in Indian Textbooks. Women and Education in the Third World. Comparative Education Review 24.2, S209-S223.

[13] Key, M. R. (1975). Male/Female Language. Metuchen, NJ.: The Scarecrow Press.

[14] Lakoff, R. (1975). Language and Women's Place. New York: Harper and Row.

[15] Lee, J. F. K. \& P. Collins (2006). Gender Representation in Hong Kong English Textbooks. The Hong Kong Institute of Education. The University of New South Wales, Australia. http://www.eoc.org.hk /eoc/upload/20067 11112336211 184.pdf (accessed 26/2/2013).

[16] Mills, S. \& L. Mullany (2011). Language, Gender and Feminism: Theory, Methodology and Practice. London and New York: Routledge.

[17] Mirza, M. (2004). Gender Analysis of School Curriculum and Text Books. UNESCO: Islamabad. http://www.un.org.pk/unesco/documents/publications/education/Gender\%20Analysis\%20of\%20School\%20Curriculum\%20and $\% 20 \mathrm{Text} \% 20$ Books.pdf (accessed 15/4/2013).

[18] Ndura, E. (2004). ESL and Cultural Bias: An Analysis of Elementary Through High School Textbooks in the Western United States of America. Language, Culture and Curriculum 17.2, 143-153.

[19] Nilsen, A. (1977). Sexism in Children's Books and Elementary Classroom Materials. In A. Nilsen, H. Bosmajian, H. Gershuny \& J. Stanley (eds.), Sexism and Language. Urbana, Illinois: National Council of Teachers of English, 161-179.

[20] Özdoğru, A. A., G. Aksoy, N. Erdoğan \& F. Gök (2004). Content Analysis for Gender Bias in Turkish Elementary School Textbooks. Proceedings of the sixteenth annual Ethnographic and Qualitative Research in Education conference. http://www.albany.edu/ eqre/papers/39EQRE.pdf (accessed 5/2/2013).

[21] Peterson, S. \& T. Kroner (1992). Gender Biases in Textbooks for Introductory Psychology and Human Development. Psychology of Women Quarterly 16.1, 17-36.

[22] Porreca, K. L. (1984). Sexism in Current ESL Textbooks. TESOL Quarterly 18.4, 704-724.

[23] Poulou, S. (1997). Sexism in the Discourse Roles of Textbook Dialogues. Language Learning 15, 68-73.

[24] Sleeter, C. \& C. Grant (1991). Race, Class, Gender and Disability in Current Textbooks. In M. W. Apple, \& L. K. ChristianSmith (eds.), The Politics of the Textbook. London, UK: Routledge, 78-110.

[25] Thomas, L. (2004). Language, Society and Power: An Introduction (2nd ed). Ishtla Singh \& Jean Stilwell Peccei. London and New York: Routledge.

[26] Thorne, B. \& N. Henely (eds.) (1975). Language and Sex: Differences and Dominance. Rowley, MA: Newbury House.

Mahnaz Hall is currently a PhD candidate at Monash University, Melbourne, Australia and is employed as a teaching associate and research assistant within the School of Languages, Cultures, and Linguistics at Monash University. She has also taught English in EFL/ESL settings in various countries for over a decade. Her research interests concern phonology, English as an international language, and lingua franca. She has some publications on phonology, and recently one of her papers was presented at the Applied Linguistics Association of Australia National Conference in Perth, Western Australia. 